\title{
Australia y el problema de las inversiones extranjeras
}

\begin{abstract}
JOHN PHILIP FOGARTY es Profesor de Historia Económica de la Universidad de Melbourne, Australia. Actualmente está concluyendo su tesis doctoral sobre "El Papel de los Ferrocarriles en el Desarrollo Económico de Victoria en el Siglo XIX". Ha publicado diversos trabajos de su especialidad en la Australian Economic History Review, $y$ en otras publicaciones académicas.
\end{abstract}

Como todas las regiones de colonización reciente, Australia ha debido basar su desarrollo económico en un alto grado de dependencia externa, lo cual se ha traducido en la excesiva confianza, para satisfacer sus necesidades de capital, en los préstamos de ultramar. Sin embargo, las inversiones extranjeras sólo ocasionalmente suscitan discusiones entre sus habitantes y no han originado polémicas semejantes a las que surgen en el Canadá, América Latina e incluso Europa, a pesar de que la dependencia ha sido un tema estudiado en profundidad por los científicos nacionales, quienes interpretan la historia económica de Australia dentro del marco de relaciones del Imperio Británico. ${ }^{1}$

En el pasado, no obstante, surgió un resentimiento en contra del inversionista extranjero, a raíz de las depresiones de 1890 y 1930. $\mathrm{El}$ desastre económico de aquellos años fue atribuido tanto a la excesiva dependencia frente al crédito externo como a la rapacidad de los financistas internacionales. En 1930 éstos últimos solicitaron al gobierno ajustes deflacionarios en la economía del país, petición que fue, muy en especial, una de las causas del resentimiento que culminó cuando el gobiemo de Nueva Gales del Sur, dirigido por J. T. Lang, decidió repudiar el pago de los intereses debidos a los accionistas británicos.

'Principalmente Fitzpatrick Brian, British Imperialism and A ustralia 1783-1833 y The British Empire in Australia: An Economic History 1834-1939, Melbourne University Press, Melbourne, 1949. 
A pesar de estas actitudes aisladas, la politica más persistente, de parte del gobierno y pueblo australiano a través de los años, ha sido la aceptación y el estímulo para la inversión de ultramar, sin preocuparse mayormente por la posesión y control extranjeros de los recursos australianos.

Recientemente ha ido creciendo, sin embargo, la corriente de preocupación por este sistema de control extranjero sobre las empresas nacionales y la explotación de los recursos del país; esta inquietud se hizo patente en el Acta despachada xápidamente por el Parlamento del Commonwealth, en noviembre de 1972, y también en los programas de todos los partidos que se presentaron a las elecciones federales, en diciembre último, quienes incluyeron propuestas para el control de la posesión extranjera sobre las empresas nacionales.

El objeto de este artículo es estudiar este giro reciente, que contraría la historia de las inversiones extranjeras en Australia.

Antes de la depresión de 1890, la nación dependia en torma excesiva del capital extranjero. A partir de 1870 y hasta el comienzo de la depresión, las inversiones absorbían cerca del $20 \%$ del producto nacional neto, y las importaciones de capital aportaban entre el 50 y el $60 \%$ de dichas inversiones, siendo Gran Bretaña la mayor fuen. te de fondos. Una parte importante del gasto australiano de capital estuvo constituida por las inversiones para infraestructura hechas entre 1870 y 1880 . Al terminar este período la formación de capital se reparte equitativamente entre los sectores público y privado.

Todos los gobiemos coloniales solicitaron préstamos masivos en Londres para financiar la construcción de ferrocarriles, caminos, sistemas de agua potable y otras empresas de utilidad pública. En el sector privado, el capital se dirigió hacia la industria lanar, la construcción residencial, la mineria y las actividades comerciales. ${ }^{2}$

En contraste con las clos décadas que precedieron a la depresión finisecular, los veinte años anteriores a la Primera Guerra Mrundial fueron por sobre todo, un período de exportación de capitales. La retirada de capital británico después de la crisis de 1893 se compensó rápidamente con la afluencia de inversiones para el desarrollo de la minería en el Oeste australiano. Desde 1904 hasta 1911, sin embargo,

¿N. G. Butlin, The Shape of the Australian Economy 1861-1900, The Economic Record, vol. 34, 1958; Australian Domestic product, Investment and Foreign Borrowing 1861-1938/39, Cambridge University Press, London, 1962, Tabla 5. 
se produjeron repatriaciones anuales de capital, siendo satisfechas ampliamente todas las necesidades del sector público con los recursos domésticos. ${ }^{3}$

En el periodo entre las guerras, el capital se formó básicamente con la inversión extranjera. En los años 20, el país financió más del $20 \%$ de su inversión con la afluencia de fondos externos. Este fue un período de empréstitos gravosos conseguidos por el gobierno y que explican la procedencia de los dos tercios de las entradas de capital. El rasgo más importante en esta afluencia de capitales fue su ingerencia en el campo de la industria y el comercio privados, donde las inversiones directas del exterior, prevalecientes frente a las de portafolio constituyeron alrededor del $25 \%$ del total invertido.

Durante el período entre las guerras, los Estados Unidos comenzaron a contribuir significativamente a la formación del capital australiano. Los préstamos conseguidos en Nueva York alcanzaron al $20 \%$ del total obtenido para 1920, e igual cosa sucedió en el sector privado.*

Desde la Segunda Guerra Mundial se observan cambios considerables en la estructura de la inversión extranjera. Si bien los créditos obtenidos por el gobierno predominaron hasta la Segunda Guerra, en los años posteriores se acentúa el flujo de inversiones privadas las que constituyeron cerca del $90 \%$ de la corriente de capitales extranjeros. En contraste con los bonosı a interés fijo en que se basaron los créditos públicos anteriores a la guerra, los capitales privados llegaron en forma de inversiones directas. También después de la guerra hubo un pronunciado cambio en la fuente de recursos externos. En los primeros años de post-guerra, Gran Bretaña continuó siendo la principal fuente de estos recursos. Los EE.UU. aumentan su contribución durante el período de los años cincuenta y sesenta y toman la delantera después de esta fecha. Asimismo, el Japón y los países europeos llegan a ser importantes fuentes de capital para Australia. ${ }^{5}$

\section{III}

Es digno de observar que el predominio de los EE.UU. como principal contribuyente coincidió con el alza del sentimiento popular en con-

${ }^{3}$ N. G. Butlin, op. cit., Tablas 255, $261 \mathrm{y}$ Colin Forster (ed.), Australian Economic Development in the Twentieth Century', Allen y Unwin, London, 1970, p. 85.

"Foster Colin, op. cit., pp. 86, 89.

${ }^{5}$ Commonweath Bureau of Census and Statistics, Overseas Investment 1970-71, p. 18, Tabla 2. 
tra de la tenencia extranjera. Al mismo tiempo se hicieron serios esfuerzos para valorar las consecuencias para la economia nacional de esta continua dependencia del capital extranjero. Lo notable es que, cuando en 1960 hubo reacciones contrarias a las inversiones extranjeras, sólo el $10 \%$ del total invertido provino de las entradas de capital foráneo, cifra magra si la comparamos con aquéllas del siglo $\mathrm{XIX}$ o las del periodo entre las guerras. Si bien la guerra de Vietnan y otros aspectos negativos cle la política estadounidense, agitados en su contra por la izquierda, sirven para relacionar demasiado fácilmente a la inversión americana en el exterior con el imperialismo yankee, los comentaristas capacitados no se alarmaron por el total de la suma sino por la naturaleza cambiante del flujo de capitales.

En 1954, cuando Nurkse hizo notar las diferencias entre el carácter de la inversión internacional de comienzos de la post-guerra, con aquél del siglo XIX, como rasgo más notorio surge el predominio de las inversiones directas en compañías privadas y la clisminución del financiamiento internacional público ${ }^{6}$. Uno de los primeros ensayos que tratan de evaluar el impacto cle esta nueva concepción en la economía australiana, dedujo que, aunque los beneficios para ella sobrepasarian probablemente el costo de las operaciones crediticias, para evitar problemas a largo plazo en la balanza de pagos era menester tomar mediclas que dirigiesen los fondos extemos hacia las actividades de exportación o las industrias de sustitución de importaciones.

Los economistas nativos han estudiado de preferencia las consecuencias a largo plazo de la inversión foránea directa para la situación de la balamza de pagos. De modo general, han tratado de separar lo que en esencia pertenece a lo económico de los aspectos políticos y cle otros argumentos emocionales que a menudo caracterizan la discusión sobre la inversión extranjera en Australia. El veredicto ha sido positivo, en cuanto a las ventajas que para el país significó la entrada de capitales extranjeros en las décadas posteriores a la post-guerra, pero éstas podrían haber aumentado con una mejor dirección y mayor control de esas inversiones por parte del gobierno. Para la economía australiana, los recursos cle capital, la tecnología y la capacidad cle administración de las empresas, que aportaron los socios extranjeros, fueron claramente ventajosos, pero persiste la ducla sobre si con una adecuada política reguladora estas ventajas hubieran podido ser aún mayores. ${ }^{7}$

BNurkse Ragnar, "International Investment in the light of Nineteenth Century Experience, Economic Joumal, LXIV, dic. 1954, pp. 744-758.

${ }^{7} \mathrm{H}$. W. Overseas Borrowing: The new Model, Economic Record, vol. 33, agosto de 1957, pp. 247-261. Arndit subrayó posteriormente que exageró con res- 
Aparte de posibles problemas posteriores de balanza de pagos, se pueden eliminar o disminuir los costos de la inversión externa con medidas adecuadas. Lo que hizo falta en Australia fue una política destinada a coorclinar la inversión extranjera con otras áreas de la actividad económica. Es notable la protección tarifaria a la industria manufacturera, que alentó a varias firmas para instalarse en el país. Cuando otras firmas internacionales quisieron competir en el mercado australiano, se produjo inmediatamente la fragmentación y la creación de capaciclad ociosa en la inclustria. La elevada estructura de costos de la industria australiana, en parte consecuencia de los altos niveles de protección tarifaria, militó contra el desarrollo de las exportaciones. Esta situación ruinosa, típica de muchas empresas con capitales extranjeros, tales como la automotriz, no puede imputarse a la inversión de ultramar, sino a deficiencias en las tarifas aplicadas y al fracaso de los esfuerzos gubernativos en pro de la coordinación efectiva de su política económica. ${ }^{8}$

Pasado el período de post-guerra se ha producido un marcado cambio en el tipo de industrias que atraen al capital exteriox. En las

pecto a la asociación entre problemas con la balunza de pagos a largo plazo, $y$ la inversión directa del exterior. Véase del autor: A small rich industrial counlyy', Cheshire, Melboume, 1968, pp. 31-35.

Las principales contribuciones sobre el tema, además de la de Arndt, op. cit., han sido: Conmonwealth of Australia, Repori of the Committee of Economic Enquiry, informe Vernon, 2 volúmenes, Canberra, 1965, Capitulo 1I; D. T. Brash, American Invesment in Australian Manufacturing, Canberra, Australian National University Press, 1966; B. L. Johns, Private overseas investment in A ustralia: profitability and motivation, Economic Record, vol. 43, junio de 1967, pp. 233-261; W. M. Corden, Protection and Forcign Investment, Economic Record, vol. 43, junio de 1967, pp. 209-232; W. P. Hogan, British Investment in Australian mantlfacturing: the technical connections, Manchester School of Economic and Social Studies, vol. 35, mayo de 1967, pp. 133-166; Foreign Investment and Capital Inflows, The English Scottish and Australian Bank Limited Rescarch Lecture, 1968, Queensland University Press, 1968; G. D. A. Mac Dougall, The benefits and costs of private investment from abroad: a theoretical approach, Economic Record, vol. 36, marzo de 1960; G. G. Moffat, The forcign ownership and balance of payments effects of direct investment from abroad, Australian Economic Papers, vol. 6, junic de 1967, pp. I-24; J. O. N. P. Perkins, Some fallacies about overseas borrowing, Australian Quarterly, vol. 32, junio de 1960, p. 74-88; E. L. Wheelwright, Overseas Investment in Australia en Alex Hunter (ed.). The Economics of Australian Industry, Melbourne University Press, Melbourne, 1963, pp. 141-173; Development and dependence: the australian problem, The Australian Quarterly, vol. 43, septicmbre de 1971, pp. 22-39.

'Para la discusión de algunos aspectos en este problema ver: L. G. Melville, Tariff Policy, The Economic Record, vol. 43, junio de 1967, pp. 193-208; Alex Hunter, The Economics of Australian Industry, Melbourne University Press, Melbourne, 1963; Commonwealth Bureau of Census and Statistics, Overseas Participation in Australian Manufacturing Industry $1962-63$ and 1966-67, Primera partc, Tenencia extranjera, p. 2. 
dos últimas décadas ha declinado la inversión extranjera en la industria manufacturera, en proporción al total de lo invertido en el área privada. En tanto que en el año 56-57, cerca de tres cuartos de la inversión privada directa se dirigió hacia la industria manufacturera, en 1969-70, sólo un cuarto de ésta se volcó en ese sector. Desde mediados de 1950 hasta la mitad de 1960, la caída de la participación del sector manufacturero en la inversión externa total se compensó con un alza por parte del comercio, y también de la construcción, las finanzas y propiedades. Desde mediados de 1960 aumentó el flujo directo de capitales hacia compañías privadas de la mineria y las exploraciones petrolíferas. La producción primaria, incluyendo a la minería y el petróleo en los años 1963-64, representa solamente el $7,7 \%$ de tales inversiones, pero. subió en 1969-70 al $30 \%$.

En tanto el capital externo se concentró en el sector de las manufacturas, era obvio reconocer sus conveniencias, que superan manifestaciones esporádicas de descontento relacionadas con la propiedad extranjera de las compañias, y que se manifiesta en las peticio. nes para lograr un nivel equitativo entre las empresas nacionales y las foráneas. No cabe la menor duda acerca de las ventajas que significan para el desarrollo la tecnología, las crecientes oportunidades de empleo y el "know-how" introducidos por las compañias transoceánicas. Para 1966-67, el 22,2 \% del valor de la producción manufacturera se repartió entre firmas de capital externo.

Estas empresas tienen, además del alto nivel de participación en la manufactura nacional, un aporte enorme en aquellas industrias que requieren fuertes inversiones de capital, como la automotriz, con el $90 \%$ de su capital en manos extranjeras, o la química pesada y la farmacéutica, con un $80 \%$, $y$ finalmente la industria del aluminio y alúmina, donde alcanza al $75 \%^{9}{ }^{9}$

Pero aunque se acepta esta penetración del capital foráneo, e incluso se lo estimula con la política impositiva del gobierno, ya no hay tan buena acogida para la adquisición de nuevas industrias nacionales por parte de empresas extranjeras. In 1960 se produjo un aluvión de compras de compañías nacionales que parecían desventajosas para Australia. Las noticias referentes a la compra de molinos locales, y de fábricas de pan y mantequilla, por parte de uno de los grandes consorcios alimenticios y tabacaleros mundiales, hizo surgir un clamor nacionalista en muchos nativos, y esta preocupación se hizo sentir en una frase rápidamente popularizada: "Han vendido

${ }^{9} \mathrm{E}$. A. Boehm, Twentieth Century Economic Development in Australia, Longmans, Melbourne, 1971, p. 113. 
nuestro campo"10. Este sentimiento de venta aguijoneado por la injustificada toma de posesión de varias compañías nacionales se agravó con la entrada de capital en los años 60 , que fomentó la participación extranjera en los sectores minero y comercial.

La explotación de la vasta reserva de hierro en la parte occidental del continente requería capital en escala muy superior a los recursos nacionales. El alcance de la inversión extranjera en la industxia minera en este período se revela en el hecho de que mientras en 1963 , el $26,6 \%$ del valor de lo producido en minería se asignó al capital extranjero, en 1967 esta proporción subió al $41 \%$ \% ${ }^{11}$

El sector rural ha recibido últimamente esta penetración de capital, que siendo pequeña en comparación con la participación de éste en los ya enunciados rubros, dio lugar a enfrentamientos, causados muy especialmente por la adquisición norteamericana, principalmente, de áreas escasamente pobladas en el Norte, donde han llevado ganado en pie, instalandose en el "top end" y en el Noroeste de Australia Occidental.

El pueblo australiano, que tiene un complejo de culpa casi patológico frente al raleamiento de población de su territorio, expresado periódicamente en campañas que solicitan "poblar y desarrollar el Norte", no ha arriesgado, sin embargo, su capital o trabajo en la causa del desarrollo nacional. En 1971, Six William Gunn, primer presidente de la Junta de Lanas, gran terrateniente y cabeza de una importante compañia expresó su desilusión de que los australianos no se interesasen en absoluto, en contribuir con capitales para su empresa, pero que se indignaran porque los americanos dieran brincos de alegría ante la oportunidad de participar en ellas. ${ }^{12}$

Este vuelco del interés externo hacia la industria lanax y minera, provocó respuestas distintas a las suscitadas cuando ello ocurrió en el sector manufacturero. Generalmente se hacían críticas a la participación extranjera en la industria manufacturera, por el porcentaje altísimo de ganancias que se remitía al exterior:- Crece el resentimiento contra la propiedad extranjera en la minería y la ganadería; en este caso la preocupación se centra en la dirección de los capitales nativos, para lucro de extraños, sin objetarse el monto de las ganancias sino la expropiación de riquezas. "El campo está vendido", "se ha dividido el país", son Erases populares que reflejan este sentimiento.

\footnotetext{
${ }^{10}$ Fitzpatrick Brian y E. L. Wheelwright, The Highest Bidder, Lansdowne Press, Melbourne, 1965, Capitulo 10.

${ }^{11}$ Commonwealth Bureau of Census and Statistics, Overseas Participation in Australian Mining Industry, 1967, p. 13.

${ }^{12}$ Ray Aitchison, Thanks to the yanks?, Sun Books, Melbourne, 1972, nos entrega una versión actualizada de las actividades norteamericanas en Australia, especialmente en los capitulos 9,10 y 12.
} 
Mr. Al Grassby, un parlamentario laborista que se identifica con esta causa, advirtió en un programa radial efectuado durante las elecciones en noviembre de 1972, que 350 millones de acres en el territorio australiano eran de posesión extranjera, así como el $71 \%$ del mineral exportado.

El hecho de ver que su país está siendo explotado por intereses foráneos demasiado poderosos para controlarlos, lleva a que muchos nativos se interesen nuevamente en el debate en torno a la propiedad externa de las empresas; hoy el imperialismo yankee es un concepto real para los australianos que piensan que quizás su país se vio presionado por el conflicto vietnamita, y se preguntan en qué medida el destino económico de su patria deberá decidirse en las salas de directorio de las grandes corporaciones multinacionales radicadas fuera del país.

El traslado del capital externo desde la manufactura hacia su concentración en los sectores primario y comercial, fue probablemente causa de un cambio en la actitud del público con respecto a la inversión foránea.

\section{IV}

Tradicionalmente, los gobiemos han alentado al capital externo, basándose en al "laissez faire", regla modificada cada cierto tiempo con ajustes muy cuerdos para encauzar las condiciones políticas y monetarias. Algunas "vacas sagradas" tales como las aerolíneas, la radio y televisión, los servicios bancarios, están protegidas del dominio extranjero y controladas por una legislación especial, y estando los ferrocarriles y demás servicios de utilidad pública bajo control de agencias gubernamentales no ha existido la desconfianza hacia el inversor extranjero que late en otros países. Sin embargo las medidas para controlar la inversión externa, que anunció recientemente el gobiemo representan una afirmación de la actitud frente a ella.

El acercamiento del gobierno hacia las empresas de control externo se caracteriza por su pragmatismo más que por su ideología. En 1965 hubo preocupación por las prácticas de algunas empresas que lograron obtener fondos en el país sin dar participación a los nativos. En mayo de ese año, el tesorero Mrr. Holt anunció que se darian directrices para ser aplicadas por el "Reserve Bank"13, que

${ }^{23}$ Commonivealth of Australia, Parliamentary Debates (House of Representatives), 13 de mayo de 1965, pp. 1525-1527. 
dieron como resultado colocar bajo vigilancia las propuestas de compañias transoceánicas para subscribir préstamos. La principal finalidad de esas orientaciones era lograr un control de todo préstamo tramitado por aquellas firmas.

No obstante, esa inquietud frente al manejo externo continuó creciendo, siendo así como en 1968 el gobierno intervino para prevenir que una compañía de seguros australiana, la "Mutual Life and Citizens Assurance Company Limited", fuera puesta bajo el control de una compañía de seguros británica ${ }^{14}$. Después vino una propuesta destinada a dar a las firmas nacionales el derecho de enmienda sobre sus artículos de asociación con el propósito de aseguxar que el control permaneciese en manos australianas. ${ }^{15}$

El 16 de septiembre de 1969, el primer ministro Gorton anunció una amplia gama de leyes para la inversión extranjera ${ }^{16}$ aclarando que su objetivo era dar estímulos a la participación nativa en los negocios externos. Se reiteraron disposiciones para créditos, incluyendo el ítem de que si una firma extranjera quisiera ofrecer participación en Australia se le abrirían las puertas para créditos, cuyo monto estaría en estricta relación con el grado de ingerencia nativa en el manejo de ésta.

El código de posesión de la compañía se fortaleció al requerirse a toda persona en posesión del $10 \%$ o más del capital de empresas registradas en la Bolsa de Comercio y con derecho a voto en ella, la obligación de intervenir en sus decisiones dando cuenta al gobierno de cualquier pretensión de tomar el mando por el sector extranjero, en caso de verse afectado el interés nacional.

De igual forma y para mejorar la fortaleza financiera de las industrias nacionales, se estableció la Corporación Australiana para el Desarrollo de la Industria, en 1970, cuyo propósito es conseguir préstamos en el exterior y hacerlo aprovechable para la industria nacional a través de créditos $y / 0$ inversiones equivalentes en ellas. Este organismo fue creado especialmente para permitir a las firmas nacionales acceso al flujo de capital externo, con el fin de desarrollar proyectos sin tener que fusionarse con una compañía extranjera. ${ }^{17}$

Desde 1965 el gobierno ha mostrado creciente inquietud por los problemas que presenta la tenencia externa pero, al mismo tiempo, no ha sido ágil en cuanto a tomar acciones que pudieran amedrentar a los capitalistas extranjeros. La política gubernamental en ma-

${ }^{14}$ Commonwealth of Australia, Parliamentary Debates (House of Representatives), 13 de mayo de 1965, pp. 1525-1527; 24 de septiembre de 1968, p. 1366.

${ }^{25}$ The Australian Economic Review, ${ }^{\text {st }}$ Quarte, 1969, pp. 45, 46.

${ }^{10}$ Ibid., 16 de septiembre de 1969, pp. 1382-1387.

${ }^{17} I$ bid., 5 de mayo de 1970, pp. 1597-1603. 
Jolun Fogarty / Australia y el moblemn de lns inrersiones extranjeras

teria cle inversión se funcla en una firme convicción de que el beneficio para el país es mayor aceptando la participación extranjera sin mediclas proteccionistas, ya que es perfectamente factible solucionar cualquier problema usando la persuasión en lugar de fuertes controles y reglamentos. Sin embargo, en estos dos últimos años la situación varió fundamentalmente: hasta 1970 la afluencia de capital hacia Australia igualó al déficit en cuenta corriente, pero descle esta fecha el flujo neto aparente de capital ha excedido este déficit, sienclo las cifras $\$ 598$ millones en 1970-71, contra $\$ 1.443$ millones en 1971-7218. Por tanto la entrada de capital privado tiende a sumarse, simplemente, a las reservas, internacionales de capital australiano, en vez de ser utilizado para incrementar los recursos aptos para la economia. El Primer Ministro Mac Mahon anunció medidas para controlar esa situación cambiante, el 27 de septiembre de 1972.

Tres de estas medidas se dirigen al problema del control de la afluencia neta del capical, ciñéndose la cuarta al control exterior de la industria. Se abolieron directivas para créditos que databan de 1965 y también las clisposiciones que prohibian la inversión en portafolio para los residentes australianos. El Reserve Bank turo que rechazar solicitudes de intercambio para préstamos en el exterior pagaderos en dos o más años. Con ello se buscó retener el flujo excesivo de capitales de ultramar. La cuarta medida trataba de imponer un control estricto sobre el control exterior. Esta legislación se despachó rápidamente en el Parlamento, para permitix al gobierno la prevención en contra de la administración foránea, que pudiera interferir el interés nacional.

El control extranjero fue claramente definido como una adquisición cle parte de cualquier consorcio extranjero del $15 \%$ o más en acciones de una Compañia australiana, o cuando los socios extranjeros tuviesen sobre el $40 \%$ del poder de voto en una firma nacional. Debería establecerse un comité independiente que analizara tocla propuesta, informando luego al gobierno. Si éste decidiera que un control determinado afecta el interés nacional, tendría que tomar en cuenta factores como el hecho cle que, luego de tomar el mando, la firma en cuestión tuviera prácticas conforme al interés nacional en relación a la exportación, importación, procesamiento local de materia prima, investigación y clesarrollo. Otro aspecto importante sería que hubiese algún conflicto con los objetivos gubernamentales para defensa, protección del medio ambiente y desarrollo regional.

Estas nuevas medidas que se dieron a conocer en forma precipitada para proveer al gobierno de una legislación que lo favoreciese

${ }^{18}$ Ibid., 26 de septiempre de 1972, p. 1917. 
en las elecciones, representan una actitud de endurecimiento hacia la inversión extranjera, ya que, como lo clijo Mac Mahon, la nación australiana no depende tanto del capital extranjero como en el pasado, pudiendo llegarse a negociar ciertos beneficios de la participación exterior, para aumentarlos en el área de la industria y comercio.

Por más que este problema de tenencia extranjera no era un tema predominante en las elecciones, todos los partidos se pronunciaron al respecto, para complacer a sus lectores, a quienes creyeron aptos para enfrentar este tema. Ciertamente existen expectativas de que el nuevo gobierno laborista use enérgicamente los controles ya establecidos que apuntan hacia una nueva actividad en la inversión foránea. Todo ello indica una nueva actitud frente al capital externo por parte de Australia. Por espacio de veinte años los nativos reconocieron que su rápido desarrollo como comunidad industrial dependió de la inversión externa, pero hoy se está consciente de que ya el país vive con independencia y aun cuando sean necesarios fondos del exterior, ha llegado la hora de cambiar los términos del intercambio. Habrá, pues, una presión mayor hacia el gobierno para asegurarse que los beneficios del capital externo no vayan en contra del bienestar supremo de la nación.

\section{V}

Los economistas se interesan muchísimo por el estudio de la relación entre desarrollo y dependencia, planteándose cuándo y cómo un pais dependiente puede arrojar su dependencia sin arriesgar su desarrollo. Esta pregunta se la plantean recién hoy los australianos $^{19}$, quienes han sido afortunados en su experiencia con el capital externo. Es necesario preguntarse si esta experiencia ha sido producto de circunstancias históricas especiales, que han predispuesto a Australia a tener una relación más positiva, en comparación con los países de América Latina, o habrá que esperar cómo se dan en Australia los aspectos dañinos de esta inversión.

Albert Exirschman sugirió recientemente que si bien la inversión extranjera puede ser una fuerza vital en las etapas primarias del desarrollo económico al contribuir al escaso contingente de medios de producción, se ha llegado a un extremo que pareciera impedir

${ }^{10}$ En la vanguardia de los que plantearon esto se sitúa E. L. Wheclwright, Development and Dependence: The Australian Problem, The Australian Quarterly, vol. 43, septiembre de 1971, pp. 22-39; Fitzpatrick and Wheelwright, op. cit.; R. Aitchison, op. cit. 
el crecimiento, posibilidad que surge cuando los empresarios locales no saben responder al desafío que significa competir con firmas extranjeras, y venden. Por lo tanto, Hirschman piensa que el clima atractivo en una etapa inicial con respecto al capital foráneo deberá cambiar, pasando a una actitud más cerrada en la etapa intermedia20. Wheelwright señaló que si bien en Australia se llevaron a cabo ambas políticas no puede aún predecirse cuál predominará. ${ }^{21}$

El problema para proyectar medidas apropiadas para el control de las actividades foráneas consiste en que deben transarse con las poderosas corporaciones multinacionales que poseen hoy la mayor parte de las inversiones internacionales.

Un economista latinoamericano señaló que la actuación de éstas firmas ya sobrepasa las fuerzas del mercado libre e incluso las medidas nacionales. No sólo los países dependientes están sujetos al control externo, sino que también se ejerce sobre ellos un control de sus importaciones. 22

La historia reciente demostró cómo las compañías multinacionales pueden tomar represalias contra los planes de gobiernos nacionalistas, cuando entran en conflicto con sus intereses. En Chile ${ }^{23}$ se tuvo una clara muestra de ello, culminando con la acusación del Presidente Allende ante la Asamblea General de las Naciones Unidas, el 4 de diciembre último, de que las corporaciones multinacionales atentaron en contra del interés de Chile.

Esta advertencia de Allende ${ }^{24}$ debe servir a toda nación, porque implica la denuncia de que la estructura política del mundo está siendo torpedeada por las poderosas compañias que no rinden cuenta ante ninguna institución representativa del interés colectivo.

El dilema que hoy enfrentan los gobiernos es que toda economía moderna depende de la fuerza de renovación y de las finanzas de las gxandes compañias, para alcanzar su máximo potencial de crecimiento; así se explican las palabras de Servan-Schreiber, cuando señala que es imposible pretender expropiax el know-how técnico y la capacidad de invención, por lo cual el país que pretende controlar las actividades de las firmas foráneas camina hoy con mucho cuidado

\footnotetext{
${ }^{\circ} \mathrm{A}$. O. Hirschman, How to divest in Latin America and why, Princeton Essays in International Finance, $N$ P 76 , November 1969, pp. 4-9. El argumento suyo fue muy criticado por Virgil Salera en Liquidate U.S. Direct Investments? Inter-American Economic Affairs, XXIV, 1970, pp. 31-40.

${ }^{21}$ Wheelwright, op. cit., p. 36.

"Osvaldo Sunkel, Big Business and "Dependencia": a latin american wiew, Foreign Affairs, vol. 50, abril de 1972, pp. 521-522.

${ }^{2}$ Theodore H. Moran, The alliance for Progress and the Foreign Copper Companies and their Local Conservative Allies' in Chile 1955-1970, vol. 25, No 4, 1971-72, pp. 3-24, en Inter-american Economic Affairs.

${ }^{24}$ Age, Melbourne, 6 de diciembre de 1972.
} 
ESTUDIOS INTERNACIONALES

para no espantar a la gallina de los huevos de oro, pero aún pueden Jos gobiernos establecer sus prioridades y asegurar que no paguen un precio muy alto por el hecho de albergar gigantescas compañias internacionales.

Australia se encuentra en una posición afortunada, ya que todaría puede obtener lo mejor de ambos mundos. Puede mantener un clima favorable para la inversión y asegurar el control sobre su destino. El problema en el pasado ha sido que los nativos no hicieron esfuerzos para mantener a sus gobiernos conscientes frente a esta realidad. A lo largo del siglo la inversión extranjera ha tenido un papel conductor en el desarrollo económico nacional y no se sabe aún si la inquietud creciente por las actividades de los inversionistas foráneos que se trasluce en la reciente legislación, buscando controlar la inversión externa, representa una nueva toma de conciencia de los peligros de la dependencia. 